\title{
Música, educação e vida cotidiana: apontamentos de uma sociografia musical
}

\section{Music, education and everyday life: notes of a musical sociography}

\author{
Jusamara Souza $^{1}$
}

\begin{abstract}
RESUMO
O artigo relata o processo e partes dos resultados de uma sociografia musical feita em uma pequena cidade localizada no Rio Grande do Sul. A pesquisa foi desenvolvida por meio de questionários e entrevistas realizadas durante visitas ao município, contatos com grupos musicais organizados e conversas com músicos locais. O objetivo foi analisar as relações entre práticas musicais existentes, a inserção destas práticas na comunidade e suas potencialidades para a educação musical. A partir dos dados obtidos, discute-se como a música na escola pode dialogar com a vitalidade cultural da comunidade na qual está inserida.
\end{abstract}

Palavras-chave: educação musical; sociologia da música; vida cotidiana.

\begin{abstract}
This article describes the process and some outcomes of a musical sociography taken in a small town located in Rio Grande do Sul - Brazil. The research was carried out through questionnaires and interviews, developed during visits to the municipality, contacts with organized musical groups, and conversations with local musicians. The aim was to analyze the relationships among existing musical practices, the inclusion of these practices in the community and its potential for musical education. Based on the data obtained, the article discusses how music in school can dialogue with the cultural vitality of the community in which it operates.
\end{abstract}

Keywords: music education; sociology of music; everyday life.

DOI: $10.1590 / 0104-4060.36584$

1 Universidade Federal do Rio Grande do Sul. Porto Alegre, Rio Grande do Sul, Brasil. Rua Professor Annes Dias, $n^{\circ} 112,15^{\circ}$ andar. Centro. CEP: 90020-090. 


\section{Introdução}

$\mathrm{Na}$ área de educação musical há muito se utiliza um conceito alargado de formação musical, entendendo que a dimensão educativa está presente nas práticas musicais realizadas em diferentes contextos, sejam eles escolares ou não escolares. Tanto como área de conhecimento ou como campo de trabalho, a educação musical considera toda prática músico-educacional como objeto de interesse e estudo. Para Kraemer (2000) a educação musical "ocupa-se com as relações entre pessoa(s) e música(s) sob os aspectos de apropriação e transmissão" (p. 65). O desafio tem sido, então, fazer o diálogo entre as diferentes formas de apropriação e transmissão do conhecimento musical produzidos socialmente. Para a educação musical escolar isto significa estar atento às formas de ensinar e aprender música que são feitas no mundo cotidiano vivido (SOUZA, 2008).

O campo escolhido para a realização dos trabalhos de pesquisa, foco do presente artigo, foi Salvador do Sul, uma pequena cidade de colonização alemã localizada no Rio Grande do Sul, situada a $100 \mathrm{~km}$ de Porto Alegre. O contato com o município de Salvador do Sul estabeleceu-se em 2010, quando foi proposto à Prefeitura, em parceria com a Universidade Federal do Rio Grande do Sul, através do Grupo de Pesquisa Educação Musical e Cotidiano² (CNPq/ UFRGS), um curso de formação continuada para professores que atuavam na rede municipal de ensino. Como desdobramento dessa ação para 2011, além da continuidade da formação de professores, foi sugerida a realização de um estudo que abrangesse as práticas musicais do Município.

O estudo proposto pelo Grupo de Pesquisa Educação Musical e Cotidiano refere-se a parte das atividades que foram desenvolvidas no âmbito do Programa "Música, Cotidiano e Educação", que havia sido selecionado e contemplado pelo Edital no 05 - PROEX/ 2010 - SESu/ MEC. Este Programa (PROEX/ 2010UFRGS) articulou as ações propostas e desenvolvidas pelo Grupo de Pesquisa Educação Musical e Cotidiano (CNPq/ UFRGS) e foi estruturado em três eixos norteadores: a) Cursos de Formação Continuada para Professores, oferecidos para as redes de ensino público e privado, de quatro regiões do país, nas cidades

2 O Grupo de Pesquisa Educação Musical e Cotidiano (CNPq/ UFRGS), vinculado ao Programa de Pós-Graduação em Música da Universidade Federal do Rio Grande do Sul (UFRGS), foi criado e coordenado pela autora deste artigo, e desenvolve suas atividades desde 1996, tendo como objetivo analisar a música e suas relações com a educação, na perspectiva das teorias do cotidiano. Ao longo desse tempo, em suas atividades regulares (de pesquisa, extensão e discussão) em torno dessas relações entre música, teorias do cotidiano e práticas educativas, o Grupo de Pesquisa tem tido como participantes todos os orientandos de mestrado e doutorado da sua coordenadora, assim como pesquisadores e professores visitantes nacionais e estrangeiros. 
de Marabá (Pará), Duas Estradas (Paraíba), Uberlândia (Minas Gerais), Maringá (Paraná), Salvador do Sul e Gramado (Rio Grande do Sul); b) Elaboração de material didático com a produção digital de um DVD e a publicação de uma coleção ${ }^{3}$ com cinco livros, com referências curriculares e propostas de atividades a serem desenvolvidas nos diferentes níveis da educação básica (infantil, fundamental e médio) e na educação de jovens e adultos; 3) Articulação de uma rede nacional com instituições de ensino superior para a criação de um banco de dados e de espaços para a divulgação e publicização das ações implementadas.

Desta maneira, ao longo de 2011 e 2012 foi realizada uma pesquisa intitulada Música na Escola: mapeamento e diagnóstico de equipamentos culturais e práticas na educação musical. ${ }^{4} \mathrm{O}$ objetivo foi identificar as atividades musicais desenvolvidas, analisar as relações entre elas e a inserção destas práticas na comunidade, bem como discutir suas potencialidades para a educação musical, analisando como a música na escola poderia dialogar com a vitalidade cultural da comunidade na qual está inserida.

Neste artigo serão apresentados achados desta pesquisa, dentro de um recorte, resultante das entrevistas qualitativas realizadas junto a músicos de nove grupos musicais e três músicos da cidade de Salvador do Sul.

\section{Cenário da pesquisa}

A cidade de Salvador do Sul possui aproximadamente 7.000 habitantes ${ }^{5}$, em sua maioria constituída de descendentes de alemães. $\mathrm{O}$ território, com "paisagens deslumbrantes" como os gestores o descrevem, faz parte do Vale do Caí, localizado na Serra Gaúcha. A história do município é marcada pela colonização alemã a partir de 1855 e, hoje, além dos descendentes de alemães,

3 Esta Coleção pertence à Série "Educação Musical e Cotidiano", coordenada por Jusamara Souza e publicada pela Tomo Editorial de Porto Alegre. Nesta série, já foram publicados dois livros: a) em 2011, "Música na Escola: Propostas para a implementação da lei 11.769/08 na Rede de Ensino de Gramado, RS", organizado por Jusamara Souza; e b) em 2013, "Educação musical, cotidiano e ensino superior", organizado por Ana Lúcia Louro e Jusamara Souza. Compõem ainda esta Série: "Educação Musical e Cotidiano" e os outros três livros que têm previsão de publicação para 2014, com os títulos/temas: "Música, Educação e Projetos Sociais"; "Pesquisa Qualitativa em Educação Musical"; e "Temas para o ensino de música na escola".

4 A equipe de pesquisadores compreendeu Jusamara Souza (Coordenação geral), Renita Klüsener (UFRGS), Matheus de Carvalho Leite (Mestrando/ UFRGS) e Ana Claudia Specht (Doutoranda/ UFRGS).

5 Dados do Censo do IBGE, de 2010. 
há uma diversidade cultural composta pelas etnias italiana, lusa, sírio-libanesa e africana. A cidade se orgulha de possuir o primeiro trilho curvilíneo da América do Sul, como uma marca da implementação da rede ferroviária que interligava Salvador do Sul aos municípios-polos do Estado e fator de desenvolvimento da região, no início do Século XX até o final dos anos 1970, quando então a ferrovia foi desativada.

Diferentemente de outras cidades do interior brasileiro, em que a maioria dos municípios não conta com nenhum tipo de equipamento cultural, nem com políticas públicas na área de música, Salvador do Sul tem um movimento artístico-musical intenso, com diversos corais, bandas escolares, bandas de rock e outros grupos instrumentais inclusive mantendo uma escola municipal para o ensino de artes. Pode-se fazer menção, aqui, à Oficina Municipal de Artes de Salvador do Sul (OMA), que disponibiliza gratuitamente mais de 20 oficinas à comunidade, entre as modalidades de música, dança, teatro, esportes e ginástica. A cidade faz parte de uma região em que há numerosos coros de tradição germânica, justamente frutos dessa colonização alemã. Portanto, a presença de muitas atividades musicais pode ser explicada pela relação dos descendentes de imigrantes alemães com a música, especialmente na tradição de coros sejam eles vinculados à igreja ou não. A relação entre as diversas atividades musicais faz da cidade um campo fértil quanto à questão identitária por agregar, além de alemães, imigrantes descendentes de italianos e outras culturas na vida musical da cidade.

Neste artigo será feito um recorte da realidade da produção musical apresentando-se grupos e músicos atuantes na cidade, como eles se veem e são vistos, como convivem com outros músicos e o que pensam sobre a música na educação. Para isso, na sequência, serão apresentadas algumas referências teóricas importantes e a metodologia empregada na pesquisa.

\section{Enquadramento teórico do estudo}

A música tem sido objeto de estudo de vários sociólogos e cientistas sociais. Para Bozon (2000), a prática musical é um "fenômeno transversal, que perpassa toda a sociedade" e que "constitui um dos domínios onde as diferenças sociais ordenam-se da maneira mais clássica e marcante, mesmo se os agentes sociais, mais seguido e constantemente que em outros campos se recusem a admitir que a hierarquia interna da prática é uma hierarquia social" (p. 147). O autor, apoiado na noção de campo social de Pierre Bourdieu, conclui: "longe de ser 
uma atividade unificadora no que concerne todos os ambientes sociais e todas as classes, a música é o lugar por excelência da diferenciação pelo desconhecimento mútuo; o gosto e os estilos seguidamente se ignoram, se menosprezam, se julgam, se copiam" (p. 147).

Bozon (2000) realizou uma pesquisa na qual descreve e analisa práticas de grupos musicais presentes em Villefranche-sur-Saône, uma pequena cidade operária na região de Lyon, França, procurando "extrair as características gerais do campo local que as constituem" (p. 148). As atividades musicais selecionadas emergiram como um campo privilegiado para se observar as diferenças entre os grupos sociais. A música é investigada como um fenômeno de sociabilidade e a análise sociológica do campo musical, feita por Bozon, ilustra esta função em nível local.

A lógica de funcionamento do campo musical é definida pelos agentes que aí atuam: músicos, promotores, crítica, organizações e pelas justificativas, incluindo a hierarquização dos agentes no campo da música e suas relações. O estudo de Bozon revela que "as características sociais, geográficas e culturais de uma pequena cidade aglutinam atividades e grupos sociais que tudo, na sociedade global, tende a separar, o que, por um efeito perverso, reforça em cada indivíduo a vontade de marcar suas distâncias.” (BOZON, 2000, p. 148).

Entender a música como prática social significa compreender que as exigências técnico-musicais estão ligadas às práticas de sociabilidade nos grupos, na família, na escola, na igreja e na comunidade. Como escreve Anne Marie Green (2000), a música é um objeto complexo por se tratar de um fato social total que coloca em jogo e combina aspectos técnicos, sociais, culturais e econômicos. A partir dessa perspectiva "que busca ter uma visão do conjunto das relações que se tecem, isto é, entendendo a música como uma realidade social com seus múltiplos aspectos" (GREEN, 2000, p. 34), a autora acredita que podemos ter uma compreensão mais aguda, mais sensível e mais larga dos fatos musicais. Esse entendimento mais ampliado, sobre o significado social da música, é útil para compreender as diferentes práticas musicais dos diversos grupos de estudantes na escola ou em outros espaços.

Além disso, para o campo pedagógico musical, esta perspectiva pode também revelar "por que estudantes de diferentes grupos se envolvem em certas práticas musicais, por que evitam outras e como respondem à música na sala de aula" (GREEN, 1997, p. 33). Dessa forma, como já discutido em outros textos (SOUZA, 2004), o que estaria no centro da aula de música seriam as relações que os alunos constroem com a música, seja ela qual for. Por isso é mais importante definir o tipo de relação que os alunos mantêm com a música do que "se limitar a um estudo da prática ou do consumo musical unicamente por seu conteúdo ou gênero de música apreciada ou escutada" (GREEN, 1987, p. 95). 
O fio condutor da pesquisa aqui apresentada é a concepção de práticas musicais como práticas sociais apoiada na sociologia da música. Como subcampo da área de música, a sociologia da música estuda

[...] as condições sociais e os efeitos da música, assim como relações sociais, que estejam relacionadas com a música. Ela considera o manuseio com música como um processo social e analisa o comportamento do homem relacionado com a música em direção às influências sociais, instituições e grupos (KRAEMER, 2000, p. 57).

Dentre os temas investigados pela sociologia da música podemos incluir: processos de socialização musical e iniciação à música, representação dos principais gêneros e estilo musicais, manutenção e renovação de práticas musicais tradicionais, bem como "comportamentos e papéis dos indivíduos em grupos", suas "produções culturais e formas de organização da vida musical." (KRAEMER, 2000, p. 57).

Através do estudo sobre a diversidade das práticas musicais encontradas em Salvador do Sul, destacando-se a variedade dessas práticas vividas pelos músicos amadores e profissionais, buscou-se responder a dois objetivos. O primeiro relativo à elaboração de um "mapa" que pudesse mostrar a pluralidade de atividades musicais e os mecanismos de diferenciação, aproximações e tensões discutidos por Bozon (2000), bem como refletir sobre as condições de permanência, ou de declínio, de determinadas práticas musicais. O segundo objetivo foi vincular esses conhecimentos com a educação musical, especialmente aquela que se faz na escola.

\section{Metodologia}

Para os fins desta pesquisa foi utilizada uma metodologia que combinou abordagens qualitativas e quantitativas, apoiando-se na sociografia musical como instrumento de coleta e análise. A sociografia musical, "como uma descrição meticulosa da realidade" (MENDRAS, 2004, Introdução, p. xxv), constitui-se em uma ferramenta que agrega sentido ao dado quantitativo e qualitativo, e foi empregada nesta pesquisa com a finalidade de analisar situações específicas em que a cultura musical local fosse considerada. Os estudos sociográficos de 
Monteiro (2009, 2011) e Guerra (2011) contribuíram para o design metodológico adotado.

A pesquisa foi realizada no período de novembro a maio de 2012, com diferentes atividades que transcorreram entre as localidades de Salvador do Sul (comunidade-alvo) e Porto Alegre (universidade). As atividades presenciais, no município de Salvador do Sul, além da participação direta da equipe de pesquisa, contou com o apoio da Prefeitura quanto ao suporte logístico, em termos de pessoal e material. A investigação foi desenvolvida em quatro etapas: fase de planejamento, fase da coleta de informações, fase de análise dos dados e fase da divulgação dos resultados. Na fase de planejamento, a articulação da equipe de pesquisa da Universidade Federal do Rio Grande do Sul (UFRGS) com os gestores da Prefeitura de Salvador do Sul foi decisiva para um adequado e profícuo planejamento, definição e aprovação das ações na realidade do município. Com essa articulação foi possível identificar o público (representações de instituições da comunidade, comunidade escolar e gestores) a ser consultado cujas opiniões foram contempladas nos instrumentos de coleta de dados que foram construídos. Isto resultou no planejamento de uma primeira versão do roteiro, tanto para as entrevistas como para o questionário. Os critérios de escolha e seleção dos informantes foram estabelecidos, também, com a colaboração das Secretarias de Educação e da Cultura da cidade.

O questionário mapeou as atividades musicais presentes na comunidade e reuniu questões contemplando os seguintes tópicos: oferta cultural da cidade (situação presente; recursos e necessidades) com particular incidência na música; espaços de fruição musical (história, focos de divulgação e sua importância); lugar do espaço na vida musical/cultural da cidade (frequência do espaço); hábitos de lazer; programação artística (tipo e localização dos espetáculos promovidos pela prefeitura e outras instituições) e conhecimento de grupos musicais e músicos.

Com a preocupação de captar as dimensões qualitativas no campo musical, foram utilizados dois tipos de entrevistas, individuais e coletivas. Através de contatos pessoais ou por telefone, foram selecionados como participantes músicos, bandas e grupos representativos da comunidade. As entrevistas individuais foram realizadas enfocando o histórico social de determinadas práticas, escolares e não escolares, com a música na comunidade; trajetórias de vida profissional e musical; modos de aprendizagem de música e grau de investimento na música. As entrevistas realizadas com os grupos musicais, em um número total de nove, permitiram identificar seus componentes e descrever as práticas musicais típicas de cada grupo.

O roteiro utilizado para as entrevistas foi estruturado a partir de quatro eixos: identidade (quem são os músicos), alteridade (como se veem e são vistos), 
interação (como convivem com outros músicos na comunidade) e educação musical (o que pensam da música na educação). Esse roteiro permitiu explorar distintas visões, estilos e temporalidades presentes na vida musical da cidade. Além disso, o roteiro incluiu o relato de momentos vividos e de contato com a música ao longo da vida (infância, adolescência, juventude e vida adulta); agentes/instâncias de socialização (amigos, irmãos, pais, tios, professores) e experiências marcantes (concertos, festivais, saídas, viagens, entre outras).

Além da elaboração dos instrumentos de coleta de dados, a equipe recebeu uma formação para se qualificar em pesquisa, ao longo de todo o projeto. Assim, com o foco dirigido aos aspectos quantitativos da sociografia musical, o cronograma previu ações de qualificação para a equipe em dois momentos: a) para a análise de estudos e pesquisas (desenvolvidas e em desenvolvimento), sobre metodologias e técnicas de coleta de dados; e b) para a sistematização das informações com o uso do software SPHINX .

$\mathrm{Na}$ fase da coleta de dados, os contatos com funcionários da Prefeitura de Salvador do Sul foram importantes para a catalogação das experiências musicais do município e o pré-agendamento de encontros com responsáveis pelos grupos musicais. Depois foi feito um agendamento para visita in loco para aplicação do questionário, captação de imagens e entrevistas de caráter qualitativo, visando à definição das experiências musicais para a produção do documentário. Os questionários foram aplicados presencialmente e também disponibilizados via web.

A etapa análise dos dados foi constituída de dois momentos complementares: a análise dos dados quantitativos resultantes dos questionários e a análise dos resultados qualitativos, com a finalização do documentário e a impressão do DVD. A produção audiovisual esteve relacionada com a articulação da equipe da UFRGS, Prefeitura Municipal de Salvador do Sul e uma produtora especializada nos serviços de captação de imagens e produção do documentário.

A última etapa, a da divulgação dos processos envolvidos no mapeamento e discussão dos resultados da pesquisa, incluiu quatro subtarefas, também importantes, a saber:

- Produção do teaser do documentário com o olhar da diversidade musical no município de Salvador do Sul, que foi apresentado no Seminário "Música, Cotidiano e Educação/PROEXT2010" realizado em 05 de dezembro de 2011 na UFRGS;

6 Ver: $<$ http://sphinxbrasil.com/produtos/sphinx-educacao>. Como indicado na página do site: "O controle dos acessos e das respostas é realizado através da identificação nominal ou por um sistema de chave que assegura condição de anonimato. A coleta das respostas pode ser realizada via rede local, dispositivos móveis, via papel ou diretamente na Web. Diferentes relatórios (com diferentes níveis de acesso à informação) podem ser estruturados de modo a atender diferentes públicos". Acesso em: 14/05/2014. 
- Sistematização das informações relativas aos equipamentos culturais na comunidade local e às práticas musicais na comunidade escolar, realizadas no município de Salvador do Sul, considerando o mapeamento já elaborado por institutos como IBGE e INEP;

- Divulgação do documentário através do seu lançamento oficial para a comunidade de Salvador do Sul, com a participação dos músicos participantes da pesquisa, ocorrido em junho de 2012;

- Elaboração de atividades didáticas a partir do documentário e divulgação do material no Curso de formação de professores, realizada em fevereiro de 2013, em Salvador do Sul.

Para efeitos de exposição neste artigo, foram reunidas e sistematizadas as informações derivadas das entrevistas qualitativas que foram realizadas.

\section{A música na vida cotidiana da comunidade}

A presença da música numa cidade pode ser captada a partir de testemunhos individuais. A música, como "um fenômeno transversal que perpassa a sociedade" (BOZON, 2000), apresenta-se em uma comunidade local de uma maneira singular, mas dotada de valores e crenças que resultam na identidade cultural do município. Para conhecer quem são os grupos e os músicos de Salvador do Sul e também como a música entrou em suas vidas, que tipo de música eles fazem, e como ajudam a construir a identidade cultural desta comunidade, foram entrevistadas pessoas pertencentes aos 9 grupos de músicos selecionados para participarem desta pesquisa. Esses grupos musicais são: Orquestra Jovem (16 participantes), Coral Bom Progresso (20 participantes), Coral Concórdia (19 participantes), Coral Municipal de Salvador do Sul (25 participantes), Quarteto da Fumaça (4 participantes), Happy Brass (10 participantes), Banda Blue Label (5 participantes), Banda Viva Alegre (9 participantes) e Banda da Escola Estadual de Ensino Médio São Salvador (25 participantes). Além desses grupos pudemos contar com o depoimento de músicos praticantes de diferentes gêneros: Ademir Holderbaun e mais três de seus familiares, também Charles Wentz e Padre Pedro Norberto Link. Além dos músicos ${ }^{7}$ que colaboraram com

7 Da lista de informantes privilegiados, entre os músicos integrantes dos grupos que colaboraram com a pesquisa, podemos nomear: Adriano Roberto Krahl, Anderson Adão Petry, Ari Gastão Petry, Arnésio Guilherme Goetz, Arsênia Maria Weschenfelder, Christian Inácio Vogt, Cinara Tamara Neis, Daniel Gonçalves de Azevedo, Elaide Petry Loff, Elton Schneider, Emerson Gastão Petry, Eunice Inês Rauber Weschenfelder, Felipe Lermen Petry, Joaquim Lunckes, José Marcos, 
seus depoimentos, foi possível ouvir outras pessoas ${ }^{8}$ da comunidade envolvidas com o tema da pesquisa. Estas pessoas estavam ligadas ao setor da administração municipal e contribuíram, decisivamente, para fornecer o apoio logístico para os trabalhos que foram realizados, facilitando os contatos, agendamentos, locais para realização do processo de coleta e produção do material audiovisual. Além disso, elas também colaboraram para a definição dos critérios de escolha e seleção dos entrevistados dos grupos musicais, além de ajudarem a localizá-los.

Diferentemente de outros estudos no campo das ciências humanas e sociais, nesta pesquisa a revelação da identidade dos participantes tem um valor científico e sócio-histórico, apoiado em dois aspectos relevantes. Um deles refere-se ao fato de que utilizar o espaço da produção e publicação científica - como aqui, em um artigo resultante de uma pesquisa realizada - para dar visibilidade à identidade destas pessoas significa também recuperar a memória de participação delas na construção dos diferentes espaços de convivência na cidade, ainda mais quando praticamente elas foram as pioneiras na região. O outro aspecto a destacar está, também, no fato de que isto adquire o significado de respeito e valorização para com estas pessoas, dando-lhes legitimidade como construtoras e participantes da história musical de Salvador do Sul. Contudo, é imprescindível assinalar aqui que a realização das entrevistas e recolha dos depoimentos, com a explicitação da identidade dos participantes, somente aconteceu após a garantia da compreensão, esclarecimento e anuência a respeito do projeto que estava sendo desenvolvido. Isso produziu a concordância e, mais ainda, a alta disposição em quererem participar e fazer parte dessa história que, então, iria ser contada e sistematizada de maneira científica e com o compromisso de torná-la pública e registrada. No documentário, um dos resultados finais das produções do projeto e que foi objeto de uma solenidade pública para sua divulgação envolveu a comunidade, os entrevistados e as autoridades que apoiaram e contribuíram na realização do trabalho - encontram-se nele os dados de identificação de todas estas pessoas que compuseram o plano de atividades do projeto.

Apresentam-se aqui os depoimentos fornecidos através das entrevistas realizadas com os músicos, bandas e grupos representativos da comunidade de Salvador do Sul. O caráter qualitativo das entrevistas permitiu que as distintas visões, estilos e temporalidades presentes na vida musical da cidade, assim como

Luis Augusto Steffens, Mateus Kremer, Otto Weimer, Paulo Candido Bard, Rejane Maria Gräf Käfer, Renê Vier, Rodrigo Calleari, Samuel Friederich, Samuel Vier, Sita Weimer, Valdir Pedrozo e Werno Bourscheid.

8 Carla Maria Specht, José Valdir Mildner, Clarina Elisabeta Klein, Rejane Maria Gräf Käfer, Zeno Evídio Becker, Cleo Marciano Meurer, Mari Beatriz Folleto Koester, Júlia Maísa Weschenfelder, Joaquim Inácio Lunckes e Ladi Maria Renner. 
experiências e vivências marcantes (individuais e comunitárias em relação à música), pudessem ser captadas através do relato desses participantes.

\title{
Identidade: quem são os músicos
}

Um primeiro eixo do roteiro de entrevistas girou em torno do conceito de identidade, avaliando as relações e imbricações do entrevistado com a música. Para isso foram considerados aspectos como gosto musical e ligação com a música, marcos biográficos e suas relações com as atividades musicais desenvolvidas e estilos musicais preferidos.

Vila (2012), ao discutir o papel da música e das dinâmicas identitárias, afirma que "toda atividade cultural (incluindo a música) é entendida como a esfera privilegiada na qual se constrói o ethos de um grupo" (p. 257). Conforme Vila, referindo-se ao musicólogo inglês Simon Frith, "a música constrói nosso sentido de identidade através das experiências diretas que oferece do corpo, do tempo, da sociabilidade, experiências que nos permitem localizarmo-nos em narrativas culturais imaginativas" (FRITH, 1996 apud VILA, 2012, p. 263). Esta última frase é, segundo Vila, "crucial" para o entendimento da relação entre música e identidade proposta por Frith, ou seja, "a música nos dá uma experiência real do que poderia ser o ideal", e conclui:

\begin{abstract}
Nesse sentido, a música é um artefato cultural privilegiado, uma vez que nos permite a experiência real de nossas identidades narrativizadas imaginárias. Assim, parte da compreensão de que nossa identidade (que sempre é imaginária) seria produzida quando nos submetemos ao prazer corporal da execução ou escuta musical. E é precisamente aí que se produz a conexão entre a interpelação e o desejo, entre a oferta identitária e a identificação (VILA, 2012, p. 261).
\end{abstract}

Em outras palavras, "a música nos dá a possibilidade de realmente vivenciar no corpo as identificações ideais (em termos étnicos, nacionais, etários, de gênero etc.) que cremos ter inscritas nele (mas que, na realidade, são apenas performativas)" (VILA, 2012, p. 266).

Através da análise das informações obtidas nas entrevistas, percebe-se que a dimensão identitária da música apareceu muito ligada à questão da etnicidade. Isso pôde ser observado especialmente na relação dos descendentes de imigrantes alemães com a música. A prática coral na comunidade tem um papel fundamental e configura-se como um espaço de sociabilidade e de encontro. Uma 
participante do Coral Bom Progresso confirma: "O canto coral é um elemento cultural que é muito presente nas nossas comunidades daqui".

Matter (2012), ao investigar sobre os processos que mobilizam encontros de grupos corais teuto-brasileiros católicos na região nordeste do estado do Rio Grande do Sul, relata que o canto coral praticado por essas comunidades "estabelece redes de circulação e de construção identitária como resultado de um processo que contribui para a atualização da cultura e da música." Ancorados na herança cultural alemã, esses grupos corais interagem, estabelecendo "redes de identificação" que "interconectam comunidades." (p. 1). Este é o caso também do Coral Concórdia, um coral centenário do município, que "procura cultuar suas tradições, suas raízes", e realiza um baile anual ("sempre no sábado mais próximo do dia 7 de janeiro") para o qual convida os demais coros da região para irem até Salvador do Sul. Elaide Loff, participante do Coral Concórdia há 30 anos, conta: "No último baile tivemos 600-700 pessoas compartilhando e prestigiando o canto coral." O repertório do coro é basicamente música sacra para cantar na igreja, mas eles também se apresentam em outros lugares.

Se essa prática coral procura manter a tradição alemã, outros testemunhos de coristas mais velhos deixam entrever a descontinuidade das práticas corais, especialmente pensando nas novas gerações e na manutenção da tradição coral:

Francamente nosso coral [Concórdia] é bom, mas não vai durar não, porque jovem não entra mais, e os velhos vão, de pouco a pouco, saindo. Isso não vai durar muito tempo não. Jovem não se interessa por cantar. Eles tem seu futebol, tem TV e seus bailes... internet... (Otto Weimer)

Os jovens trabalham em fábricas e quando voltam, eles estão cansados e não vão para os ensaios (Sita Weimer)

Ainda vinculado à questão dos descendentes de imigrantes alemães e sua identidade com a música, o depoimento do Padre Pedro Norberto Link é emblemático. Aqui, ele faz um recorte da história da imigração alemã local, revelando parte da herança cultural alemã na educação musical escolar, construída no Colégio Santo Inácio, um espaço ainda referência para a educação do município:

Eu sou Padre Pedro Norberto Link, de origem alemã. Eu cheguei aqui em 1941 juntamente com um grupo bastante grande, viemos de trem, enchemos um vagão, em Santo Ângelo [RS]. Se a gente olha por ali é 
a coisa mais maravilhosa, os vales, os montes, mas ali de cima, mais acima no morro a gente chega a ver até Porto Alegre. Para construir o colégio, os tijolos vinham de trem. Por aqui passaram cerca de 3.000 , um pouquinho mais que 3.000 alunos. Ao todo [o colégio funcionou] foi de 37 a 90. Em 90 foi fechado, tristemente, foi fechado.

No começo era português, aritmética, geografia, história, música... era teoria e também a prática e chegamos a formar uma orquestra aqui. Eu não me lembro quantas figuras eram, mas enchiam mais ou menos uma sala assim... Eu me lembro de um canto Alleluia, de Haendel, era cantado no dormitório, na Páscoa. Então, isso era... aquilo enchia de fato o coração. Eu fui destacado para trabalhar aqui como mestre, como professor e para cuidar do grupo de alunos. Aí eu comecei a juntar dinheirinho pra comprar uma dúzia de gaitinhas e uma dúzia de flautas. Eu entreguei o dinheiro para um padre alemão que daqui ia para a Alemanha e lá, na Alemanha, havia dois estudantes jesuitas. Então, eu pedi para ele entregar o dinheiro, comprar as gaitinhas e mandá-las depois pra cá. Chegamos a tocar pros benfeitores de Montenegro9. Acho que alugamos uma Kombi pra colocar a turminha e fomos, passamos o dia lá, tocando pra rapaziada, foi um dia de folga e deram muita alegria pros benfeitores.

A citação, embora longa, dá uma ideia de como os imigrantes alemães trataram de movimentar o campo da música na educação e o legado desse movimento para a comunidade. Como escreve Bozon,

a originalidade do campo musical está no fato de que, cobrindo um espaço social muito extenso ele permite a observação simultânea de continuidades e de descontinuidades, favorecendo no mais alto grau o espírito de encenação por parte dos agentes (BOZON, 2000, p. 172).

Alteridade: como se veem e são vistos

A importância da música na estruturação da identidade e no modo de vida dos entrevistados pode ser vista nos vários depoimentos. A identidade do indivíduo vai sendo construída por meio das relações socioculturais estabele-

9 Salvador do Sul foi emancipado de Montenegro em 9 de outubro de 1963, através da Lei Estadual $n^{\circ} 4.577$ e posterior alteração no artigo $2^{\circ}$. 
cidas com a família, os amigos e a escola, a mídia e as instituições religiosas, o que vai tornando-o consciente de sua singularidade, do diferente, da diferença.

Eu comecei na música com 8 anos. Na minha família parente nenhum era músico. Até hoje a gente não sabe direito porque eu tive esse gosto musical. Mas, a partir dos 8 anos, que um dia eu vi um folhetozinho de uma loja lá, um teclado, eu me apaixonei, assim, foi à primeira vista e dai eu pedi, bah, pai, eu quero esse teclado. E o pai, aquela vez, ele fez de tudo, tudo o que podia para comprar, as condições não eram assim tão boas, mas ele conseguiu comprar [o instrumento]. Talvez por esse esforço também, vendo ele fazer esse esforço por mim, é um gosto tão grande, que eu iniciei nessa parte da música. (Samuel Vier, Happy Brass)

[...] o que me levou a aprender música aos 35 anos foi que desde criança meu sonho era ser músico. Então tinha um rádio à pilha, a gente escutava as bandinhas, ai a gente ia pra roça arrumar pastos pros animais e assoviava a música, porque eu queria música! (Werno Bourscheid, Banda Viva Alegre)

O entendimento mais amplo dos significados sociais da música nos ajuda a compreender diferentes práticas musicais dos diversos grupos. Isso também revela por que os diferentes grupos se envolvem com certas práticas musicais, por que optam por outras e como essas distintas práticas se comunicam entre si.

A música fornece ferramentas que permitem aos cidadãos conhecer e se relacionar com as produções culturais e simbólicas do passado, e com aquelas produções do presente, através de sua recepção e produção. Como escreve Arroyo (2002), "as práticas musicais compreendem um complexo de aspectos, desde os produtores e receptores das ações musicais, o que eles produzem, como e por quê, e todo o contexto social e cultural que dá sentido às próprias ações musicais" (p. 29). Assim, pode-se afirmar sobre a importância desse processo para a formação de grupos e sociabilidade, como também para o respeito pela diversidade de identidades e o refinamento de uma sensibilidade multicultural. Dessa forma, se utilizada dentro de preceitos éticos e de defesa dos direitos humanos, a cultura musical de uma cidade torna-se, portanto, vital para o exercício da democracia. Essa dimensão do fenômeno musical é também sublinhada por Bozon (2000), visto que a música desempenha "um papel importante no 'vivido' pelos praticantes: seu caráter social devido ao fato de que a prática em si implica em relações entre as pessoas que tocam juntas, e induz, ao mesmo tempo, a um processo de diferenciação entre grupos de música" (p. 147-148). 
Interação: como convivem com outros músicos na comunidade

Se as práticas musicais se diferenciam pelos gêneros e pelos repertórios, elas também coexistem na comunidade. Há um esforço das políticas locais em manter as tradições culturais atentas ao processo de construção identitária do município. Isto aparece, também, no caso da Festur, "uma festa de grande relevância" que procura manter "o caráter comunitário e de preservação de patrimônio cultural" 10 , segundo o discurso dos agentes da administração. A festa reúne várias manifestações culturais da cidade (música, dança, gastronomia) tentando a cada edição inovar, despertar o interesse da população e dos turistas, mas sem perder a tradição:

É uma excelente oportunidade pra fazer o resgate do que os colonos que vieram da Europa, como que eles cantavam, como que eles dançavam, e isso é um enorme atrativo cultural que está sendo expresso aqui na Festur, e cultura é canto, cultura é dança... (Derli Paulo Bolini, Representante do Governador)

Não existe turismo sem que haja a questão do resgate cultural, do resgate da gastronomia, enfim, de todas as atividades que as pessoas desenvolvem culturalmente no seu dia a dia. (Carla Maria Specht, Prefeita)

Os depoimentos dos gestores municipais também descrevem os objetivos e as expectativas que têm com a festa. O investimento do município na Festur como uma alavanca para o turismo da região engloba as políticas de acesso à cultura e de manter vivas as tradições musicais do município:

Que através das atividades culturais desenvolvidas aqui durante a festa, que isso se estenda depois, é uma forma de trazer o público pra cá, eles verem isso e tornarem isso hábito na vida deles, participar de atividades culturais... Talvez a festa seja um instrumento que nós temos de difundir a cultura dentro do município. (Edelson Holdefer, Presidente da $9^{a}$ Festur - 2011)

10 Trata-se da Festa do Turismo de Salvador do Sul. Parte da pesquisa de campo foi feita no período da realização da Festur, em sua 9a edição, ocorrida de 11 a 15 de novembro de 2011. 
E eu acho interessantíssimo, inclusive, essa oportunidade em que os alunos da Oficina Municipal [de Artes] têm de se apresentar e mostrar aquilo que eles de fato aprendem e também acabam levando pra vida. (Clarina Elizabeta Klain, Secretária de Turismo)

Apesar da proximidade geográfica com a capital Porto Alegre, as atividades musicais observadas na Festur estão distantes dos circuitos midiáticos e com pouca interferência dos centros produtores de padrões considerados "legítimos" ou dos critérios mercadológicos de qualidade musical. Os grupos musicais funcionam com certa autonomia, com regras que parecem ter valor somente no espaço local e regional. Como uma festa popular a Festur revela aspectos das políticas culturais para o município nos quais está presente o dilema da tradição, da conservação para que a herança cultural não desapareça, mas que abarque o novo, as novas gerações. A Festur torna-se um lugar de encontro das múltiplas pertenças identitárias como a Banda Happy Brass "que leva adiante os costumes e a tradição germânica do município" e a Banda de rock Blue Label cujos membros se perguntam: "Colocar uma banda de rock 'n' roll numa cidade pequena, primeiro tu é visto assim: Pô, quê que esses caras estão tocando, entendeu?". E cantam numa composição própria:

\author{
Eu bebo um velho uísque \\ e boto uma calça surrada, \\ às vezes escuto Beatles, \\ às vezes escuto mais nada. \\ Com o meu conversível, \\ eu sou o rei da estrada, \\ devasta os cabelos, \\ o rock é uma longa jornada.
}

Vila (2012), citando Frith, escreve que "a principal razão pela qual as pessoas apreciam a música é exatamente porque ela dá resposta a questões de identidade" (p. 253) já que:

usamos canções populares para criar um tipo particular de autodefinição, um lugar particular na sociedade. O prazer que a música pop produz é um prazer de identificação - com a música de que gostamos, com os 
intérpretes dessa música, com as outras pessoas que gostam desse mesmo tipo de música (FRITH, 1987, p. 140, apud VILA, 2012, p. 253).

As relações sociais estabelecidas com a música é um dos temas examinados pela sociologia da música quando entendemos melhor o comportamento das pessoas relacionados com a música, considerando ainda os efeitos das instituições. A convivência com a família, com os grupos, nos momentos de sociabilidade, auxiliam no processo de aprendizagem musical:

Sou Ademir Holderbaun, natural da Linha Comprida, onde vivi até os 20 anos aproximadamente, trabalhando na roça, depois também com acácia, produção de carvão [...]. O pai já tocava um pouquinho algum instrumento, tocava gaita, umas e outras músicas, à noite [...]. Depois do serviço, ele ficava tocando e eu era pequeno, ficava apreciando, depois quando às vezes aparecia umas festas, mesmo que raramente a gente podia ir junto, toda vez que tinha uma festa, músico tocando, eu ficava observando. Mesmo não tendo música tocando, ficava olhando só os instrumentos. Ai, o pai, depois quando cresci um pouco, foi incentivando para eu aprender a tocar e com 13, 14 anos consegui um professor no interior [...].

Esse depoimento constitui um exemplo de processos de aprendizagem musical que são incorporados da família. Aprendizagens que são individuais, porém mediadas pela presença do pai que tocava e pelas experiências com música feitas na comunidade.

\section{Educação musical: o que pensam da música na educação}

Vários depoimentos afirmaram a importância de se incluir a música na educação e como ela pode fazer parte de um currículo de ensino. A experiência pedagógica musical não pode desconhecer a referência cultural presente na comunidade local, pois a escola é uma instituição cultural, acentuada pelas relações entre escola e cultura presentes em todo processo educativo.

Guardiões da memória musical coletiva, os músicos dizem possuírem objetivos comuns em prol do desenvolvimento cultural da cidade baseado nos princípios de cooperação, convivência, na "amizade entre os músicos", já que tocar juntos "são reencontros", e que outros grupos são "mais meus amigos que 
concorrentes, tudo é necessário" (Ademir Holderbaun). Sobretudo, os músicos estão atentos às heranças: "eu toco na Banda dos Bravos", uma referência na letra de uma das músicas da Blue Label a uma banda na qual seus pais tocavam: "O Charles [Wentz] fazia parte da banda dos nossos pais." Segundo Charles Wentz, em seu depoimento, os integrantes da Blue Label são "filhos de músicos cujos pais tinham o Grupo dos Bravos, junto conosco, e a Blue Label é uma banda que toca música nos 70, e toca 2012. É uma banda de excelente qualidade.”

É nesse contexto que é possível construir espaços entre o conhecimento universal da música e aquele conhecimento que está ali presente na cultura local, como patrimônio das pessoas que vivem e frequentam o entorno da escola.

A prática da música na escola há de ser sempre diversificada. A inserção da prática musical na escola dependerá de circunstâncias que variam com os interesses locais, com a realidade cultural e social de cada aluno(a). O importante é que a música retorne aos currículos escolares, mas principalmente, através de projetos integrando as diferentes disciplinas, valorizando e fortalecendo a cultura da comunidade.

\section{Para concluir}

Se a pesquisa de campo na origem deste artigo foi delimitada, tornando as generalizações cuidadosas, passou a ser possível afirmar que os resultados podem colaborar para um diálogo entre cultura e educação, qualificar as decisões de gestores públicos na área da educação e da cultura, bem como quantificar o potencial de práticas musicais.

O contato com os músicos locais e a realização dos encontros que impulsionaram o mapeamento deram visibilidade ao projeto junto às comunidades local e regional. Um dos resultados da pesquisa foi a produção do documentário $^{11}$ intitulado Diversidade nas Práticas Musicais: um olhar para a vitalidade cultural na comunidade de Salvador do SUL/RS. Com a duração de 35 minutos, o filme faz um registro da música na cidade, com recortes das entrevistas dos grupos e dos músicos que participam das manifestações culturais na região. $\mathrm{O}$ vídeo contribuiu para a interação, a troca de conhecimentos e a circulação de

11 Como já informado anteriormente, a produção do documentário é parte integrante do Programa Música, Cotidiano e Educação - Proext 2010, contando com a parceria institucional da UFRGS e Prefeitura de Salvador do Sul/RS. A produção do vídeo foi realizada por uma empresa especializada e contou com o apoio do Programa de Pós-Graduação em Música/UFRGS e do Grupo de Pesquisa Educação Musical e Cotidiano (CNPq//UFRGS), e com financiamento do MEC/SESU. 
informações sobre os músicos residentes no município. O rock também é uma realidade musical numa comunidade germânica? Um dos músicos entrevistados comenta: "Hoje, depois de 5, 6 anos tocando juntos, eu vejo que muita coisa mudou" (Banda Blue Label). O rock é mesmo uma longa jornada.

A relação das pessoas com a música e seus efeitos no cotidiano da cidade de Salvador do Sul - momentos, grupos, espaços - é muito significativa e por isso a relevância de estudar esse campo local de uma perspectiva compreensiva e como um fato social, investigado "a partir da experiência vivida por um grupo social sabendo-se que essa sociedade é o resultado das condutas musicais de atores singulares em relações que ligam uns aos outros" (GREEN, 2000, p. 34).

Para Green o objetivo é não sacrificar os aspectos teóricos do fato social em geral, nem os aspectos específicos do musical, que se encontram além do social, e sim conseguir colocar em evidência as suas interdependências. Como diz a autora, deve-se saber "estudar a música como uma realidade social com seus aspectos múltiplos, levando-se em conta que essas camadas se interpenetram" (GREEN, 2000, p. 34). O modelo interpretativo de Green anuncia "uma visão global da música, sem perder de vista os aspectos sociais e humanos", uma vez que a prática musical é fruto da realidade humana. Para a autora:

Não existe objeto musical independentemente de sua constituição por um sujeito. Não existe, portanto, por um lado, o mundo das obras musicais (que não são entidades universais e se desenvolvem em condições particulares ligadas a uma dada ordem cultural), e por outro, indivíduos com disposições adquiridas ou condutas musicais influenciadas pelas normas da sociedade. A música é, portanto, um fato cultural inscrito em uma dada sociedade [...]. (GREEN, 1987, p. 91; Tradução nossa).

Isso significa compreender que a música está ligada a outras esferas da vida - amigos, profissão, lazer, subjetividades, família...-e por isso a sua importância também na educação escolar. No artigo foram apresentadas e discutidas questões relacionadas à música e educação musical, recuperando-se a vitalidade cultural da cidade através das experiências e histórias vividas pelos entrevistados. Dessa maneira, a interpretação qualitativa desses indicadores do cotidiano musical e comunitário, coletados no município, colaborou para um diálogo entre cultura e educação, permitindo perceber a presença das decisões de gestores públicos na área da educação e da cultura ao potencializarem e fortalecerem práticas musicais, inclusive com a recomposição da história dessa produção na cidade. 


\section{Agradecimentos}

A autora agradece à comunidade de Salvador do Sul pelo engajamento e apoio ao projeto. Um agradecimento especial à Professora Dra. Maria de Fátima Quintal de Freitas pela leitura cuidadosa do original que deu origem a este artigo.

\section{REFERÊNCIAS}

ARROYO, M. Educação musical na contemporaneidade. In: SEMINÁRIO NACIONAL DE PESQUISA EM MÚSICA DA UFG, 2. Anais... Goiânia, 2002. p. 18-29.

BOZON, M. Práticas musicais e classes sociais: estrutura de um campo local. Em Pauta, v. 11, n. 16/17, p. 146-174, abr./nov. 2000.

GREEN, A. M. Les comportements musicaux des adolescentes. Inharmoniques " $M u$ siques, Identités”, v. 2, p. 88-102, Mai 1987.

GREEN, A. M. Les enjeux méthodologiques d’une approche sociologique de faits musicaux. In: GREEN, A. M. (Org.). Musique et sociologie: enjeux méthodologiques et approches empiriques. Paris: L'Harmattan, 2000, p. 17-40.

GREEN, L. Pesquisa em sociologia da educação musical. Revista da ABEM, Salvador, n. 4, p. 25-35, 1997.

GUERRA. P. Culturas urbanas e modos de vida juvenis: cenários, sonoridades e estéticas na contemporaneidade portuguesa (2005-2009) Tese (Doutorado em Sociologia) - Instituto de Sociologia da Faculdade de Letras da Universidade do Porto, Departamento de Sociologia da Faculdade de Letras da Universidade do Porto, 2011.

KRAEMER, R. D. Dimensões e funções do conhecimento pedagógico-musical. Trad. Jusamara Souza. Em Pauta, v. 11, n. 16/17, p. 49-73, abr./nov. 2000.

MATTER, S. S. Tão Longe... Tão Perto: A música migrante. In: ENCONTRO INTERNACIONAL DE MÚSICA E MÍDIA, 8, São Paulo, USP, 19 a 21 de setembro de 2012. Anais... São Paulo, 2012, p. 1-10.

MENDRAS, H. O que é sociologia? Trad. Albert Stuckenbruck. Barueri: Manole, 2004.

MONTEIRO, C. A. Campo musical Cabo-Verdiano na área metropolitana de Lisboa: protagonistas, identidades e música migrante. Tese (Doutorado em Sociologia) - ISCTE-Instituto Universitário de Lisboa, 2009. 
MONTEIRO, C. A. Música migrante em Lisboa. Trajectos e Práticas de Músicos Cabo-Verdianos. Lisboa: Editora Mundos Sociais, 2011.

SOUZA, J. Educação musical e práticas sociais. Revista da ABEM, v.10, p. 7-11, 2004.

SOUZA, J. (Org.). Aprender e ensinar música no cotidiano. Sulina: Porto Alegre, 2008.

VILA, P. Práticas musicais e identificações sociais. Significação, Ano 39, n. 38, p.247277, 2012.

Texto recebido em 20 de maio de 2014 .

Texto aprovado em $1^{\circ}$ de julho de 2014. 
